\title{
Learner Autonomy: A Qualitative Inquiry into Indonesian Tertiary EFL Students' Voices
}

\section{DAFLIZAR ${ }^{*}$}

\begin{abstract}
This study sought to explore Indonesian tertiary EFL students' voices on learner autonomy. Specifically, it investigated the students' conceptualization of the concept of learner autonomy, students' perceptions of the benefits of learner autonomy, and their perceptions of the factors that hinder and support the development of learner autonomy. The study employed a qualitative design with a case study approach and involved 30 first-year students of two institutions of higher education in Jambi province, Indonesia. The data were collected using semi-structured interviews were analyzed using a thematic analysis following the steps proposed by Braun and Clarke (2006). The results revealed that the students had a limited understanding of the concept of learner autonomy. However, they believed that they would benefit from learner autonomy in terms of timing, learning effectiveness, and learning resources. The students also identified several hindering and supporting factors related to the development of learner autonomy. Practical implications for the Indonesian context are discussed.
\end{abstract}

\section{Keywords}

Learner autonomy, benefits of learner autonomy, hindering factors, supporting factors, teacher's role

* Senior lecturer at the English Education Department of the Faculty of Education and Teacher Training, State

Islamic Institute of Kerinci, Indonesia; daflizar@yahoo.com 


\section{IRJE | Indonesian Research Journal in Education | | Vol. 5 | No. 2| December|Year 2021|}

\section{Introduction}

Learner autonomy, broadly defined as learners' ability to take charge of their own learning, has long been considered a desirable goal of education in many countries and is associated with lifelong learning theories and pedagogies that are affecting global educational policies and classroom teaching (Armitage et al., 2012). The rapid advancement in the digital world with a variety of learning tools has provided students with an abundance of learning resources and enables them to get entirely or partially involved in their learning. Within this shifting landscape of teaching and learning, learner autonomy is an essential element in students' learning, including in learning a foreign language. In Indonesia, it is an eminent reality that opportunities to use English in the classroom are scarce. Once students leave the classroom, the opportunities become scarcer as the students are totally immersed in their first language environments. Dissatisfaction over students' English language achievements has long become one of the main concerns despite the long history of English language teaching in this country. The outcomes are even still unsatisfactory provided that the latest curricula have advocated learner-centered approaches. Many suggest that the enduring problems do not only stem from the curriculum but also from numerous other factors including, among others, large class sizes, limited time allocation for English instruction, lack of teacher's encouragement for students' participation in the classroom activities, and students' lack of opportunity to use English out of the classroom (Dardjowidjojo, 2000; Musthafa, 2001; Nur, 2004; Weda, 2018). Despite the multifaceted problems, there remains the responsibility of finding ways to help students attain satisfactory English outcomes. While several avenues have been pursued to address these challenges, one important measure that has not been considered is the development of learner autonomy.

The literature has underscored that promoting learner autonomy is of importance because it prepares learners for long-life learning, enhances the quality of their language learning, and allows them to utilize learning opportunities both inside and outside the classroom (Cotterall, 1995; Palfreyman, 2003). Moreover, evidence indicating the practical potencies of learner autonomy has been shown by research. It has been suggested that autonomous learning leads to learners' active participation in learning activities (Dincer et al., 2012), improves language proficiency (Karatas et al., 2015), and increases motivation (e.g. Miller et al., 2005). Given its numerous advantages, learner autonomy is an important measure to develop in the Indonesian context.

However, the development of learner autonomy is not an easy and instant process. Rather, it is a gradual and complex process (Benson, 2011; Little, 2007), which is influenced by many factors, including, among others, learners' beliefs, attitudes, motivation, personality, and culture (Chen \& Li, 2014). This suggests that exploring students' perceptions of learner autonomy is an important step to take before any interventions to help students' learning are implemented. A better understanding of students' perceptions can assist the implementation of learner autonomy as a goal and make guidance given by teachers to learners more effective (Pearson, 2003). Thus, the present study aimed to answer the following research questions: 1. How do Indonesian tertiary EFL students conceptualize the concept of learner autonomy? (2) What are students' perceptions of the benefits of learner autonomy? 3. What 


\section{IRJE | Indonesian Research Journal in Education | | Vol. 5 | No. 2| December|Year 2021|}

are students' perceived factors that hinder and support the development of learner autonomy?

\section{Literature Review}

\section{Learner autonomy}

Learner autonomy has been a matter of interest in the field of language education for several decades. Yet, many definitions have been given to the term, which is partly due to diverse perspectives on what it constitutes and the many interpretations of its scope (Palfreyman, 2003). Moreover, Holec (1981) defined learner autonomy as "the ability to take charge of one's learning" (p. 3), and this definition has proved remarkably vigorous being the most frequently cited in the literature (Benson, 2007; Cotterall, 2008). Following Holec's presentation of his definition, many subsequent definitions emerged. For example, Little (1991) defines autonomy as "a capacity - for detachment, critical reflection, decision-making, and independent action" (p. 4). He is concerned with the psychological relationship the learner has both with content and the process of learning. Little further explains that the capacity for autonomy is manifested in how learners go about their learning and how they transfer what they have learned to wider contexts.

According to Benson (2001), both Holec's (1981) and Little's (1991) definitions cover two essential aspects of the nature of autonomy, i.e. learning management and cognitive capacity. However, a third fundamental aspect in autonomous learning is underestimated, that is, "that the content of learning should be freely determined by the learners" (Benson, 2001). Learner autonomy has a social aspect, which may entail control over learning situations and the need to have particular capacities regarding the learner's ability to interact with others in the learning process. Defining learner autonomy as "the capacity to take control of one's own learning" (p. 47), Benson asserts that autonomous learners are decision-makers who exercise varying degrees of control over learning management, learning content, and cognitive processes. However, this capacity does not mean learning without the investment of a teacher or as students learning in isolation. Rather, an autonomous learner interacts and develops a sense of interdependence with others in the learning process.

\section{Previous studies on students' perceptions of learner autonomy}

A number of studies have been conducted to explore students' perceptions of learner autonomy. One of the seminal studies on students' perceptions of learner autonomy was conducted by Chan (2001). The study involved 20 second-year language major students on the 'English at the Workplace' course in the Hong Kong Polytechnic University. The study explored the learners' attitudes and perceptions of language learning, teacher and learner roles, their learning preferences, and perceptions of learner autonomy. The results revealed that the students had a positive attitude towards autonomous learning, demonstrated a clear understanding of the nature of learner autonomy, and were very much aware of its demands. However, most of the participants had an uncertain attitude towards the teacher's role. 


\section{IRJE | Indonesian Research Journal in Education | | Vol. 5 | No. 2| December|Year 2021|}

While a vast majority preferred the teacher to guide them in their learning, the others liked the teacher to give them problems to solve and let them find their own mistakes.

In a similar context, Chan (2001) conducted another study that involved 30 first-year undergraduates. The study aimed at identifying students' views relating to autonomous learning through the means of a questionnaire. It specifically explored students' views of autonomous learning and autonomous learners, their perceptions of the teacher's and their own roles in learning, and their learning preferences. The results showed that although the majority of the respondents agreed that autonomous learning is important and that the majority seemed to be quite aware of the principles and practice of learner autonomy, the respondents considered the teacher's role in language learning as imperative, and they felt that the major decision making should be in the hands of the teacher.

In the Japanese context, Gamble et al. (2012) examined university students' perceptions of their responsibilities and abilities to undertake autonomous English learning, and also what they could do inside and outside the classroom based on students' motivational levels. The data were collected from 399 participants from seven universities using a questionnaire. The results showed that the students across motivational levels - the highly motivated, motivated, and unmotivated - demonstrated the same perceptions of their responsibilities in performing autonomous learning tasks. In general, regardless of motivational levels, the students preferred the teachers to be more responsible for class management and agreed to share the responsibility with the teacher in the areas related to assessment and setting learning goals. Regarding their abilities, on the other hand, highly motivated students showed a tendency to view themselves as being able to be more involved in their own learning than unmotivated students. However, they often did not manifest these perceptions in practice due to a held belief that it was the teacher's responsibility or because they had little confidence to do so.

Khalil and Ali (2018) explored the perceptions of learner autonomy of 265 students and 89 EFL teachers in technical secondary schools in Egypt. The data from the students were collected using a questionnaire and the data from the teachers were collected through a questionnaire and structured interviews. The results showed that the participants had positive views about learner autonomy in language learning. The students were generally aware of the autonomy-boosting practices and teachers' roles in fostering autonomy. The teachers also had a clear understanding of the concept of learner autonomy and were aware of its importance in EFL classes.

Swatevacharkul and Boonma's (2020) conducted a study in an international university in Thailand to explore students' attitudes toward learner autonomy. Using open-response questionnaires, the data were collected from 23 participants consisting of 19 Chinese, 3 Burmese, and 1 Thai. The results demonstrated that the participants appeared to have positive attitudes toward the concept of learner autonomy. They understood that learner autonomy is the ability for successful self-directed learning, which involves self-related, affective, and interaction aspects. The participants also acknowledged the importance of learner autonomy as motivation to learn independently.

Although a wide range of studies on students' perceptions of learner autonomy have been conducted in many non-Western contexts, very scant research on this topic has been conducted in the Indonesian context. Among the few studies that have been undertaken are 


\section{IRJE | Indonesian Research Journal in Education | | Vol. 5 | No. 2| December|Year 2021|}

Ardi (2013), Lamb (2004), Lengkanawati (2017), Myartawan et al., (2013), and Wachidah (2001), each of these studies had a different research focus. Ardi (2013) investigated autonomous behavior and English learning activities beyond the classroom. Lamb (2004) examined autonomous attitudes amongst junior high school EFL learners. Lengkanawati (2017) investigated learner autonomy as perceived and experienced by school teachers. Myartawan, et al. (2013) examined the correlation between learner autonomy and English proficiency. Wachidah's (2001) study focused on student learning styles and autonomous learning in a Javanese-dominated general high school. Taking into account a large number of educational institutions in Indonesia and the potential for research given the many facets of learner autonomy, these embody relatively few studies. This study is of significance as it attempted to address this gap and contributes to the literature on learner autonomy specifically in the Indonesian context. Moreover, the findings from previous studies are still inconclusive and it is also evidence that perceptions are contextually situated. While most of the studies cited above used questionnaires as the data collection instrument, the present study used semi-structured interviews.

\section{Methodology}

\section{Research design, participants, and locale of the study}

This study aimed to explore the perspectives of Indonesian tertiary EFL students on learner autonomy. Four research questions were formulated to guide the study, namely: 1) How do Indonesian tertiary EFL students conceptualize the concept of learner autonomy?; 2) What are students' perceptions of the benefits of learner autonomy?; and 3) What are students' perceived factors that hinder and support the development of learner autonomy? To achieve the objective of the study, a qualitative design with a case study approach was employed. According to Yin (2003), a case study is "an empirical inquiry that investigates a contemporary phenomenon within its real-life context, especially when the boundaries between phenomenon and context are not clearly evident." Thus, this approach was considered appropriate because the present study attempted to explore students' perceptions of learner autonomy in the particular context of the province of Jambi, Indonesia. Given the diversity of Indonesia's ethnic groups and cultures, an in-depth exploration of student beliefs in one regional setting was most appropriate.

The study involved 30 EFL students from two different institutions of higher education in Jambi province, Indonesia. All the participants were first-year students doing English language major and non-English language majors, they were both male and female, were from eighteen to twenty years of age, and had varied English language proficiency levels.

\section{Data collection and analysis}

The semi-structured interview type was chosen to collect the data in this study. This type of interview was appropriate for providing an understanding of students' perceptions and allowing the interviewer to ask elaboration questions. As Berg (2001) stated that in the semi-structured interview, "the interviewers are permitted (in fact expected) to probe far 


\section{IRJE | Indonesian Research Journal in Education | | Vol. 5 | No. 2| December|Year 2021|}

beyond the answers to their prepared and standardized questions" (p. 70). The rationale for choosing the interview as the data collection was that the interview "can provide insights into people's experiences, beliefs, perceptions, and motivations at a depth that is not possible with questionnaires" (Richards, 2009). Prior to the data collection, the interview questions were validated. To ensure clarity in the wording, the interview questions were pilot-tested to two non-participants of the study. The interviews were conducted based on a pre-developed set of questions. The participants were asked additional questions, depending on their responses. Since the majority of the participants had a low English proficiency level, the interviews were conducted in Bahasa Indonesia. Lopez et al. (2008) suggested that interviews should be conducted in the participants' preferred language so that they will have a clearer understanding of the issues under investigation. Each interview was planned to last about 15 minutes but some of the interviews lasted longer and each interview was audio-recorded as all the participants had consented to this. Two digital recorders in the form of mobile phones (one was used as the backup for the other) were used.

Before the data were analyzed, the audio-recorded interviews were first transcribed verbatim. After all the data had been transcribed, the transcripts were rechecked to verify that there were no obvious mistakes made during the transcription process. Then, the analysis was conducted using a thematic analysis following the steps proposed by Braun and Clarke (2006). The first step of the analysis was familiarizing myself with the data by reading through the transcripts repeatedly to gain a sense of the whole (Tesch, 1990) searching for meaning and patterns. After reading and familiarizing myself with the data, I generated initial codes by identifying the features of the data, for example, identifying text segments, placing brackets around them, and assigning a code word or phrase that precisely described the meaning of the text segment. After that, I made a list of all code words, then grouped similar codes and attempted to identify any overlap and redundancy of the codes. After all the data had been coded and organized, I then searched for themes by sorting the different codes into prospective themes and organizing all the pertinent coded data extracts within the identified themes, which produced a collection of candidate themes. Next, I reviewed the themes and refined a set of candidate themes. Finally, I defined and constructed a concise and informative name for each theme.

To ensure the trustworthiness of the data, several strategies as proposed by Merriam and Tisdell (2016) were employed. First, the data were triangulated through multiple interviews. Second, adequate time was spent in the data collection so that the data became saturated. Third, I ensured that no conflict of interest existed between me as the researcher and the participants to avoid biases that may affect the investigation. Fourth, I had discussions with experts regarding the process of the study. Lastly, I provided rich and thick descriptions to place the study in context to enhance the transferability of the findings.

\section{Ethical considerations}

All the participants were given the information form that explained the purposes of the study before they decided whether or not to participate in the study. It was emphasized in the explanation that their identity would be kept confidential and anonymous and that 


\section{IRJE | Indonesian Research Journal in Education | | Vol. 5 | No. 2| December|Year 2021|}

they were allowed to withdraw from the interview at any time. To keep the confidentiality and anonymity of the participants, pseudonyms were used in reporting the results.

\section{Findings}

The overarching purpose of the present study was to explore the perspectives of Indonesian tertiary EFL students on learner autonomy. In this section, students' responses are presented in four broad themes, i.e. 1) Students' conceptualization of the concept of learner autonomy; 2) Students' perceptions of the benefits of learner autonomy; and 3) Students' perceptions of factors that hinder and support the students' development of learner autonomy.

\section{Student's conceptualization of the concept of learner autonomy}

The first question was asked to explore how the students conceptualized the concept of learner autonomy. The results of the interviews revealed that a vast majority of the students simply defined learner autonomy as independent learning that is entirely free from the teacher. Nirina, for example, expressed, 'In my opinion, learner autonomy is how we learn without help from teachers, that is, how we strive for learning by ourselves.' In a similar vein, Putri commented, 'Learner autonomy is how a student finds his/her own ways to get knowledge without guidance from the teacher. They search for learning resources by themselves, for example by searching the internet, reading books, and so forth.' Elaborating her similar definition of learner autonomy, Rinjani said, '...university students should not be very dependent on the teacher in their learning... they should make efforts by themselves, they should be more active searching their own learning materials instead of waiting for the teacher to provide the materials for them.'

Despite the consensus, however, four students believed that autonomous learning may involve other people, including the teacher and friends. Ranti, for example, said, 'For me, learner autonomy is learning independently. But, if we have problems, we can ask for help from friends or teachers.' A similar comment was given by Andika. He stated, 'Autonomous learning means students make their own effort to learn but there are times when they need help from others.' Taufik expanded this saying, 'autonomous learning is not only when someone studies on his own without others, but it can also be learning together in a group outside class. This way, when we do not understand, we can ask for help from those who know more about the subjects being learned.' Sintia offered a similar opinion commenting, 'Besides learning in the classroom, we can also, for example, learn at home or study in groups without teachers.'

\section{Students'perceptions of the benefits of learner autonomy}

The results of the interviews demonstrated that there was an obvious agreement among the students that learner autonomy offers a number of potential benefits for students' English language learning. Seven of the students mentioned that learner autonomy practically compensates for time and resource scarcity in the classroom. Some students 


\section{IRJE | Indonesian Research Journal in Education | | Vol. 5 | No. 2| December|Year 2021|}

commented that engaging in autonomous language learning activities outside the class provides students with access to learning resources they can use to get the knowledge and skills they want. Nirina, for example, noted, 'The time allocated for English learning in the classroom is limited while outside classroom learning allows us to search for things we want to know.' Taufik commented, 'We will not always get what we need if we rely solely on the teachers. The teachers will not always be available to teach what we want to learn... So we need to extend our learning beyond the classroom.' A similar opinion was expressed by Indri, 'When you learn by yourself, you can learn what you want to learn while when you learn in the classroom you will not get all what you want to know.'

Seven of the students reported that autonomous learning can broaden students' knowledge, as expressed by Zaskia and Romi as follows:

"When we learn in the classroom, we will only get very little but when we do autonomous learning outside the class, whether by guidance from the teacher or by our own efforts, God willing, we will get more knowledge.” [Zaskia]

"It is sometimes difficult to understand the lesson when learning English together with classmates. For me, learning individually at home or taking an English course outside the institution seems more effective to me and these can also broaden our knowledge and add what we have got from the lessons in the classroom." [Romi]

Learning can be more effective and more personalized was another advantage of learner autonomy mentioned by some students. Mela, for example, commented, '...learning is more effective when you take control of your own learning. I mean, especially when learning English, it will be easier for you to remember the lessons when you continually practice them.' Indri expressed a similar comment, saying, 'Classroom learning is so limited that not all that we desire to learn can be achieved. By learning autonomously outside the class, we will get more and we can learn what we want.'

\section{Students' perceptions of factors that hinder and support the development of learner autonomy}

When asked to name the factors that hindered the development of learner autonomy, the shortage of learning resources was mentioned with the highest frequency by the students. In this respect, Zaskia, Mayang, Nirina, and Damayanti shared a similar opinion that the number of books available in the campus library or the nearby bookstore is very limited. Besides acknowledging the limited availability of English books, Kartika added that limited access to digital resources such as computers and the internet was an impediment for her to develop as an autonomous learner.

Eleven of the students said that an unsupportive learning environment was among the factors that hindered them from developing their autonomy. Rendi mentioned the people around him, for example. He said, 'If your friends do not practice autonomous learning, you will also tend not to do so.' Karmila named new technology as one factor that prevented her from being autonomous. She said, 'Sometimes I spend too much time playing 


\section{IRJE | Indonesian Research Journal in Education | | Vol. 5 | No. 2| December|Year 2021|}

with the internet and mobile phones, so I do not have time to learn.' Mayang said that when she was at home, she often had the intention to learn English but at the same time she had to help her parents to do housework.

Time shortage was another factor mentioned by 10 of the students. Zaskia indicated this in her remark, 'Sometimes I am very busy at home helping my parents doing housework so that I don't have enough time to learn.' A similar reason was expressed by Indri, 'Sometimes I have made schedules to learn but there is so much work to do at home, I have to do housework.' Under the same circumstance, Siska said that she is a married woman, thus she has limited time to learn at home. Sandi pointed out that he spent most of his time after class involved in off-campus social organizations. He said, 'I am very busy after class, I am active in some off-campus social organizations.'

Another factor reported by 4 students was a lack of financial support. Romi and Wulan, for example, suggested that learning outside the class would incur costs. Romi said, 'I do not have enough money to buy books and access the internet.' Wulan said, 'For me, the first hindrance is the financial factor. To learn outside the class we need facilities and resources such as computers and books.' A similar challenge was expressed by Kartika.

For Ranti and Eva, lack of interest was another factor that hampers the development of learner autonomy. Ranti commented, 'I feel so lazy to read English books... Even sometimes I don't attend the English classes. The very reason is that I do not like English. I am not interested in learning English.' Eva related her lack of interest to her friends' attitudes towards English. She said, 'My motivation to learn English is down when I see that my friends show no interest in learning English.'

On the factors that supported the development of learner autonomy, on the other hand, willingness to succeed was noted with the highest frequency, by 18 of the students. Mella remarked, 'Well, as a grown-up I should be autonomous... I want to succeed and I want to finish my study as early as possible.' Ayu said, 'I want to be good at English so that I can speak with foreigners, sing in English and I also have the ambition to go abroad.' Damayanti also had a similar opinion, saying that she had an ambition to master English and to go abroad. Mayang related her autonomous learning to succeed academically. She commented, 'It is natural that when we learn we want to get the highest marks among our friends. When we see a friend gets the highest marks, we will try to achieve the same.' A point to note here is that the above students all had different majors of study.

Eleven of the students mentioned that they are encouraged to develop their autonomous learning because they want to please their parents. Riana said that her parents expect her to be an English teacher. Taufik remarked that he should make use of his time to study because his parents have spent much money to pay for his study. In a similar vein, Mayang said, 'I think family is the main reason. My parents work hard to pay for my study so I have to pay their hard work back by studying seriously, this may make them happy.' It is interesting to note that in this culture parents play an important role in their children's education. It is usually the parents' responsibility to pay for their children even during higher education degrees.

Another factor, mentioned by 7 students, was a supportive environment. Putri and Rendi for example, indicated that their friends or peers played an important role in their autonomous learning development. Putri commented, '... if I have friends who are good at 


\section{IRJE | Indonesian Research Journal in Education | | Vol. 5 | No. 2| December|Year 2021|}

English, I also feel motivated to learn. Rendi shared a similar reason, saying, 'I am encouraged to learn English when I see my classmates can speak English well. This is one of the factors which increase my interest to learn autonomously.'

Some students named that willingness to broaden their knowledge is another factor that encourages them to proceed with autonomous learning activities. Siska said, 'I learn autonomously because I want to get more knowledge and become better at English'. Eko said, 'I am aware that I have limited knowledge so if I have time I will use it to learn autonomously to broaden my knowledge.'

It can be concluded that students had the interest to learn but generally lacked the resources and a supportive environment. The factors that hindered and supported the development of learner autonomy were internal, which is dependent on the individual or, external, driven by social context. Concerning hindering factors, lack of interest in learning English was internal while a shortage of learning resources, unsupportive learning environment, time shortage, and lack of financial support were external factors. Regarding the factors that supported the development of autonomy, a willingness to succeed, a willingness to broaden their knowledge and a desire to make their parents happy can be classified as internal, while a supportive environment was an external factor. It is interesting to note that the hindering factors tended to be more external. In contrast, the internal factors outweighed the external ones as factors that support the development of learner autonomy. A summary of the factors provided by the students which hindered or supported the development of learner autonomy is presented in Table 1 below.

Table 1. Factors that hinder and support the development of learner autonomy

\begin{tabular}{|c|c|c|c|}
\hline \multicolumn{2}{|c|}{$\begin{array}{l}\text { Factors that hinder } \\
\text { the development of learner autonomy }\end{array}$} & \multicolumn{2}{|c|}{$\begin{array}{l}\text { Factors that support } \\
\text { the development of learner autonomy }\end{array}$} \\
\hline Internal & External & Internal & External \\
\hline - Lack of interest & 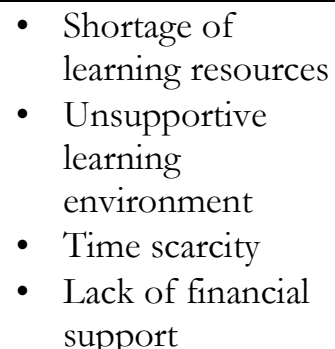 & $\begin{array}{l}\text { - Willingness to } \\
\text { succeed } \\
\text { - Making their parents } \\
\text { happy } \\
\text { - Willingness to } \\
\text { broaden knowledge }\end{array}$ & $\begin{array}{l}\text { Supportive } \\
\text { environment }\end{array}$ \\
\hline
\end{tabular}

\section{Discussion}

The first questions of this study focused on the participants' conceptualization of learner autonomy. The results showed that the majority of the students understood learner autonomy more as an action than a capacity to take control of the action. In view of this thinking, it can be inferred that there was a lack of understanding about the concept of learner autonomy among the students. The students' understanding may be best illustrated as what Lamb (2008) refers to as a "visible, external manifestation of learner autonomy", in 


\section{IRJE | Indonesian Research Journal in Education | | Vol. 5 | No. 2| December|Year 2021|}

contrast to "a more internal, less visible construction of autonomy, in which autonomous learning involves a capacity for taking control, a knowledge of how to learn as well as the motivation to learn" (p. 271). These results are different from those obtained in Swatevacharkul and Boonma's (2020) study conducted in an international university in Thailand, in which the participants consisting of Chinese, Burmese, and Thai appeared to view learner autonomy as one's capacity to manage their own learning.

It is also evident that the students excluded the role of the teacher, which is a key element of the definition of learner autonomy provided in the current literature. According to Palfreyman (2003), although the term independence is often used synonymously with autonomy, and independence from a teacher is often regarded as a noticeable sign of autonomy, current researchers suggest that a key element of the construct is that students are able to work independently but in negotiation and with support from teachers. This view of autonomy is based on Vygotsky's (1978) social interactionism point of view, which suggests that people do not learn in isolation but they learn through interactions with others. According to Little (1996), collaborative learning through social interaction is fundamental for learner autonomy because it allows the development of reflective and analytic skills in learners, which "depend on the internalization of a capacity to participate fully and critically in social interactions" (p. 211). Social strategies, especially cooperating with others belong to the most important learning strategies language learning use which encourages positive interdependence and mutual support, and are proven to have given significant benefits to language learners (Oxford, 1990).

The second question focused on students' views about the benefits of learner autonomy. It is clear from the students' responses that learner autonomy is regarded as an important aspect of language learning. The reasons for its importance are seen to be its valuable effects on student learning in terms of timing, learning effectiveness, and learning resources. The students' responses are in accordance with Richards' (2015) conclusions concerning the benefits of engaging in out-of-class learning activities, which "offer a wider range of affordances for language use and second language acquisition than are generally available in the classroom. They can provide opportunities for learners to: ... have extended contact with English... make use of multimodal sources of learning" (p. 19). These findings also confirm the benefits of learner autonomy identified in the literature, which suggest that learning will be more effective and focused when one is in charge of his own learning (e.g. Dam, 1995; Little, 1991).

The third research question investigated students' perceived factors that hinder and support the development of learner autonomy. The most mentioned was the shortage of learning resources. With regard to this, Dickinson (1987) believed that for learner autonomy to be exercised, the required materials need to be made available for learners. According to Zhao and Chen (2014), materials play a pivotal role in developing and breeding learner autonomy, predominantly because they motivate learners for their English study. The students also mentioned an unsupportive learning environment as one of the hindering factors. This matter was also identified in Lamb's (2002) study in a similar cultural context: a respondent suggested that he failed to learn English because of his unsupportive friends. Regarding this, Lamb (2002) wrote, "as if the possibility of his English learning depended on 


\section{IRJE | Indonesian Research Journal in Education | | Vol. 5 | No. 2| December|Year 2021|}

a joint agreement among his friends to do so" (p. 43). These two hindering factors were also identified in Swatevacharkul and Boonma's (2020) study in a different context.

It may be interesting to note that although some of the students suggested that they had the intention to study after class, they had to help their parents do housework. It is very common in the Indonesian context to find that children, especially women, are supposed to help their parents with in-house-related work. Also, a large body of literature has suggested that students' marital status influences their autonomy (e.g. Derrick et al., 2007; Kashefian-Naeeini \& Riazi, 2011). For example, Kashefian-Naeeini \& Riazi (2011) found that marital status affected students' autonomy in that those students who were single not only obtained higher indexes of learner autonomy in comparison with married ones, but they could also get better results in self-assessment which is one of the underlying factors of autonomy. An enormous body of literature has suggested that environmental factors, such as peers, parents, and other social variables, are important determiners of students' motivation and self-regulated behavior (e.g., Harvey \& Chickie-Wolfe, 2007; Wentzel \& Watkins, 2002). Harvey and Chickie-Wolfe (2007), for example, point out that although independent learning is considered as resulting from individual goals and behaviors, it is essentially socially mediated. Self-regulation "implies that internal forces regulate behavior, but the ability to self-regulate is predicated upon environmental variables (social, physical, and economic) that are not universally available" (pp. 24-25).

As regards the supporting factors, willingness to succeed was noted by the highest number of students. This suggests that motivation is an integral factor that influences student autonomy. In terms of Gardner and Lambert's (1972) types of motivation, the students' responses constitute expressions of both integrative and instrumental motivation. According to Dörnyei and Ushioda (2011), integrative motivation refers to "a positive disposition toward the L2 group and the desire to interact with and even become similar to valued members of that community" (p. 41). Instrumental motivation, by comparison, is related to "the potential pragmatic gains of L2 proficiency, such as getting a better job or a higher salary."

The results also indicated that a sense of obligation to their parents due to the financial support received from them was strong for the students. It is interesting to note that, in most, or even in all, Indonesian ethnic groups, parents play an important role in their children's education. The students continue to be dependent on their parents in many aspects of life including financial, even during their education at university. Thus, it is very common in this context that parents are among the reasons for students to be motivated to succeed in their education. Gratitude and responsibility towards their parents due to their financial dependency and emotional connection present a strong incentive for the students. These results are in line with Wentzel's (1998) early study which indicated that perceived support from parents predicted students' academic goal orientations. It appears from the comments made in the interviews that the students related their willingness to learn to their parents' expectations and the support they provide for them, especially financial support. This cultural element needs to be further investigated in the Indonesian context and, perhaps teaching and learning may need to be reconciled with family needs.

The students' responses to a supportive environment confirm Harvey \& Chickie-Wolfe's (2007) view that the social group to which students belong affects academic 


\section{IRJE | Indonesian Research Journal in Education | | Vol. 5 | No. 2| December|Year 2021|}

effort, habits, motivation, and time spent on academic work. "Friends can provide one another with academic support, make learning more pleasurable, and increase one another's desire to succeed academically" (p. 25). It may also be worth mentioning here that students' responses were similar to those achieved in Lamb's (2002) study that was conducted in a similar context; thef respondents mentioned, among others, willingness to succeed, their parents and friends as part of their inspiration for learning English.

With reference to the results revealed, it appeared that while both intrinsic and extrinsic factors contribute to the hindering and supporting factors, it is noteworthy that the hindering factors tend to be extrinsic, and, in contrast, the supporting factors tend to be intrinsic. Perhaps in the Indonesian context, both extrinsic and intrinsic factors should be considered when attempting to foster learner autonomy.

\section{Conclusion and Implications}

This study investigated Indonesian EFL students' perceptions of learner autonomy. Specifically, it explored students' conceptualization of learner autonomy, benefits of learner autonomy, and factors that hinder and support the development of learner autonomy. The results revealed that the students had a limited understanding of the concept of learner autonomy. Most of them conceptualized learner autonomy as independent learning and associated it with learning in isolation. The results also showed that the students believed they would benefit from learner autonomy in a number of ways, particularly: compensating for time and resource scarcity, broadening knowledge, and more effective and personalized learning. The results identified a number of factors that acted as hindrances and others that supported the development of students' learner autonomy. Among the mentioned hindering factors were a shortage of learning resources, an unsupportive learning environment, shortage of time, lack of financial support, and lack of interest. On the other hand, willingness to succeed, to please their parents, supportive environment, and willingness to broaden knowledge were the factors perceived to support the development of learner autonomy. It can be deduced from the responses that the hindering factors tended to be extrinsic rather than intrinsic and, in contrast, the supporting factors seem to be more intrinsic than extrinsic.

The findings of this study have a number of implications for further implementations. Since the teacher has an important role to play in the effort to promote learner autonomy, focusing on what the teacher can do to help students develop their autonomy is crucial. What this study revealed is students lack an understanding of the concept of learner autonomy, which calls for teachers' attention to the need for helping the students to first understand and then develop their autonomy. However, as noted earlier in this paper, the development of learner autonomy is a gradual and intricate process. Thus, shifting control from the teacher to the students is not an easy task. Little (2007, p. 26) indicates "Learner autonomy is the product of an interactive process in which the teacher gradually enlarges the scope of her learners' autonomy by gradually allowing them more control of the process and content of their learning." Hence, strategy training on autonomous learning is needed as a transitional phase during which control is gradually shifted from the teacher to students. According to Dickinson (1993), if the notion of learner 


\section{IRJE | Indonesian Research Journal in Education | | Vol. 5 | No. 2| December|Year 2021|}

autonomy implies the ability to take on more responsibility for learning, the ability must entail both strategies and confidence. Thus, training learners to act strategically and develop their confidence would enhance the efficiency of the autonomous learning process.

It should be acknowledged that setting up subjects specifically allocated to strategy training is more desirable to give thorough training to help students become autonomous. This is especially true for students in the English language major, as they are prepared to be English teachers. Rigorous training not only would enhance their autonomous ability for their own learning as pre-service teachers but also enhance their professional development giving them knowledge and skills they could apply in their teaching in the future. However, if integrating strategy training into teaching materials is the only choice, adopting learner-centered approaches along with the strategy training would be required for attempting to promote learner autonomy in the classroom. Teachers could integrate a variety of authentic and semi-authentic tasks, and also communicative tasks such as discussions, games, and role-plays to encourage student collaboration and participation. This can be expected to gradually lead to students taking more active roles and responsibilities in the classroom and develop their own individual strategies of learning autonomously. Teachers could also talk about the concept of learner autonomy in the classroom and generate discussions that allow the students to contribute to their understanding of learner autonomy. As for the strategy training, Wenden (1998) suggested that the contents should address the know-how for learning and strategies for managing learning; it could also be expanded to two sets of skills or strategies: metacognitive and cognitive strategies.

As with any research, the present study has limitations. First, since the data were collected from only two institutions of higher educations in one geographical area, the results cannot be generalized to a wider context of Indonesia. Involving more institutions from different geographical areas could increase the representativeness of the study. Second, this study used a qualitative case-study approach where the data were collected only through interviews. Employing a mixed-method approach and using additional data collection instruments such as surveys could give more detailed information about students' perceptions. Despite the limitations, the present study contributes to an understanding of Indonesian university students' perceptions of learner autonomy and identified several prospective topics of inquiry for future research. The data of the present study were gathered only from students. Future research should involve English language teachers to explore their readiness for promoting learner autonomy. Future research should also investigate students' practices of learner autonomy both inside and outside the classroom using multiple data collection instruments such as observations, classroom recordings, and portfolios to obtain information about students' autonomous learning behaviors.

\section{Disclosure Statement}

No potential conflict of interest was reported by the authors.

\section{Acknowledgments}

I would like to thanks all participants of this study for their willingness to freely share their precious experiences and insights with me. 


\section{IRJE | Indonesian Research Journal in Education | | Vol. 5 | No. 2| December|Year 2021|}

\section{References}

Ardi, P. (2013). Investigating tertiary students' autonomy in out-of-class EFL learning. Proceedings of the Asian conference on language learning 2013. http://iafor.org/archives/offprints/acll2013-offprints/ACLL2013 0282.pdf

Armitage, A., Evershed, J., Hayes, D., Hudson, A., Kent, J., Lawes, S., Poma, S., \& Renwick, M. (2012). Teaching and training in lifelong learning (4th ed.). Open University Press.

Benson, P. (2001). Teaching and researching autonomy in language learning. Longman.

Benson, P. (2007). Autonomy in language teaching and learning. Language Teaching, 40(1), 21-40. http://doi.org/10.1017/S0261444806003958

Benson, P. (2011). Language learning and teaching beyond the classroom: An introduction to the field. In. P. Benson \& H. Reinders (Eds.), Beyond the language classroom (pp. 7-16). Palgrave Macmillan.

Berg, B. L. (2001). Qualitative research methods for the social sciences (4th ed.). Allyn and Bacon.

Braun, V., \& Clarke, V. (2006). Using thematic analysis in psychology. Qualitative Research in Psychology, 3(2), 77-101. http://doi.org/10.1191/1478088706qp063oa

Chan, V. (2001a). Readiness for learner autonomy: What do our learners tell us?. Teaching in Higher Education, 6(4), 505-518. http://doi.org/10.1080/13562510120078045

Chan, V. (2001b). Learning autonomously: The learners' perspectives. Journal of Further and Higher Education, 25(3), 285-300. http://doi.org/10.1080/03098770120077649

Chen, H., \& Li, N. (2014). The analysis of factors affecting autonomy of English-major postgraduates. In S. Narayanasamy (Ed.), 2014 International Conference on Social Science and Management (pp. 250-253). DEStech Publications.

Cotterall, S. (1995). Developing a course strategy for learner autonomy. ELT Journal, 49(3), 219-227.

Cotterall, S. (2008). Autonomy and good language learners. In C. Griffits (Ed.), Lessons from good language learners (pp. 110-120). Cambridge University Press.

Dam, L. (1995). Learner autonomy: From theory to classroom practice. Authentic Language Learning Resources, (3).

Dardjowidjojo, S. (2000). ECHA kisah pemerolehan bahasa anak Indonesia. Jakarta: Grasindo.

Derrick, M. G., Rovai, A. P., Ponton, M., Confessore, G. J., \& Carr, P. B. (2007). An examination of the relationship of gender, marital status, and prior educational attainment and learner autonomy. Educational Research and Review, 2(1), 001-008.

Dickinson, L. (1987). Self-instruction in language learning. Cambridge University Press.

Dickinson, L. (1993). Talking shop: Aspects of autonomous learning. ELT Journal, 47(4), 330-336.

Dincer, A., Yesilyurt, S., \& Takkac, M. (2012). The effect of autonomy supportive climates on EFL learners' engagement, achievement, and competence in English speaking classrooms. Procedia - Social and Behavioral Sciences, 46, 3890-3894.

Dörnyei, Z., \& Ushioda, E. (2011). Teaching and researching motivation (2nd ed.). Longman.

Gamble, C., Aliponga, J., Wilkins, M., Koshiyama, Y., Yoshida, K., Ando, S. (2012). Examining learner autonomy dimensions: Students' perception of their responsibility 


\section{IRJE | Indonesian Research Journal in Education | | Vol. 5 | No. 2| December|Year 2021|}

and ability. In A, Stewart, \& N, Sonda (Eds), JALT (2011) Conference proceeding. Tokyo: JALT.

Gardner, R. C., \& Lambert, W. E. (1972). Attitudes and motivation in second language learning. Newbury House.

Harvey, V. S., \& Chickie-Wolfe, L. A. (2007). Fostering independent learning: Practical strategies to promote student success. Guilford Press.

Holec, H. (1981). Autonomy and foreign language learning. Pergamon Press.

Karatas, H., Alci, B., Yurtseven, N., \& Yuksel, H. G. (2015). Prediction of ELT students' academic (language) achievement: Language learning orientation and autonomous learning. International Online Journal of Educational Sciences, 7(1), 160-171.

Kashefian-Naeeini, S., \& Riazi, A. (2011). Beliefs and autonomy: A case of Iranian students. European Journal of Social Sciences, 20(3) 425-430.

Khalil, S, M., \& Ali, A. D. (2018). Exploring EFL teachers' and students' perceptions of learner autonomy in Egyptian technical schools. International Journal of English Language Education, 6(2), 1-25.

Lamb, M. (2002). Explaining successful language learning in difficult circumstances. Prospect, $17(2), 35-52$.

Lamb, M. (2004). 'It depends on the students themselves': Independent language learning at an Indonesian state school. Language, culture and curriculum, 17(3), 229-245.

Lamb, T. (2008). Learner autonomy and teacher autonomy: Synthesising an agenda. In T. Lamb \& H. Reinders (Eds.), Learner and teacher autonomy: Concepts, realities, and responses (pp. 269-284). John Benjamins Publishing Company.

Lengkanawati, N. S. (2017). Learner autonomy in the Indonesian EFL settings. Indonesian Journal of Applied Linguistics, 6(2), 222-231.

Little, D. (1991). Learner autonomy 1: Definitions, issues and problems. Authentik.

Little, D. (1996). Freedom to learn and compulsion to interact: Promoting learner autonomy through the use of information systems and information technologies. In $\mathrm{R}$. Pemberton, S. L. Edward, W. W. F. Or, \& Pierson, H. D. (Eds.), Taking control: Autonomy in language learning (pp. 203-219). Hong Kong University Press.

Little, D. (2007). Language learner autonomy: Some fundamental considerations revisited. Innovation in Language Learning and Teaching, 1(1), 14-29.

Lopez, G. I., Figueroa, M., Connor, S. E., \& Maliski, S. L. (2008). Translation barriers in conducting qualitative research with Spanish speakers. Qualitative Health Research, 18(12), 1729-1737. http://doi.org/10.1177/1049732308325857

Merriam, S. B., \& Tisdell, E. J. (2016). Qualitative research: A guide to design and implementation (4th ed.). Jossey-Bass.

Miller, L., Hopkins, M., \& Tsang, E. (2005). Self-access language learning in Hong Kong secondary schools. Paper presented at the 2nd Independent Learning Association Oceania Conference, Manukau Institute of Technology, Auckland, New Zealand.

Musthafa, B. (2001). Communicative language teaching in Indonesia: Issues of theoretical assumptions and challenges in the classroom practice. TEFLIN Journal, 12(2).

Myartawan, I. P. N. W., Latief, M. A., \& Suharmanto. (2013). The correlation between learner autonomy and English proficiency of Indonesian EFL college learners. TEFLIN Journal, 24(1), 63-81. 


\section{IRJE | Indonesian Research Journal in Education | | Vol. 5 | No. 2| December|Year 2021|}

Nur, C. (2004). English laguange teaching in Indonesia: Changing policies and practices in H. W. Kam \& R. Y. L. Wong (Eds) English language teaching in East Asia today: Changing policies and practices. Singapore: Eastern University Press.

Oxford, R. L. (1990). Language learning strategies: What every teacher should know. Heinle \& Heinle. Palfreyman, D. (2003). Introduction: Culture and learner Autonomy. In D. Palfreyman \& R. C. Smith (Eds.), Learner autonomy across cultures: Language education perspectives (pp. 1-19). Palgrave Macmillan.

Richards, K. (2009). Interviews. In J. Heigham \& R. A. Croker (Eds.), Qualitative research in applied linguistics: A practical introduction (pp. 182-199). Palgrave Macmillan.

Richards, J. C. (2015). The Changing Face of Language Learning: Learning Beyond the Classroom. RELC Journal, 46(1), 5-22. http://doi.org/10.1177/0033688214561621

Swatevacharkul, R., \& Boonma, N. (2020). Learner autonomy: Attitudes of graduate students in English language teaching program in Thailand. LEARN Journal, 13(2), 176-193.

Tesch, R. (1990). Qualitative research: Analysis types and software tools. Falmer.

Vygotsky, L. S. (1978). Mind in society: The development of higher psychological processes. Harvard University Press.

Wachidah, S. (2001). EFL learning autonomy and output planning: A case in a Javanese-dominated general high school (Sekolah Menengah Umum) in Indonesia [Unpublished doctoral thesis]. University of Sydney.

Weda, S. (2018). Problems in English word stress placement made by Indonesian learners of English. ELS Journal interdisciplinary Studies in Humalities, 1(3), 328-341.

Wenden, A. L. (1998). Learner training in foreign/second language learning: A curricular perspective for the $21^{\text {st }}$ century. ERIC Document Reproduction Service No. ED 416 673.

Wentzel, K. R. (1998). Social relationships and motivation in middle school: The role of parents, teachers, and peers. Journal of Educational Psychology, 90(2), 202-209.

Wentzel, K. R., \& Watkins, D. E. (2002). Peer relationships and collaborative learning as contexts for academic enablers. School Psychology Review, 31, 366-377.

Yin, R. K. (2003). Case study research: Design and methods. SAGE

Zhao, X., \& Chen, W. (2014). Correlation between learning motivation and learner autonomy for non-English majors. World Transactions on Engineering and Technology Education, 12(3), 374-379.

\section{Biographical Notes}

DAFLIZAR is a senior lecturer at the English Education Department of the Faculty of Education and Teacher Training, State Islamic Institute of Kerinci, Indonesia. He obtained his Master's degree in TESOL and Ph.D. degree in Education (TESOL) from the University of Canberra, Australia. His research interests include learner autonomy, language learning strategies, language teaching and learning, technology-based language learning, and language learning motivation 